\title{
STRATEGIC INTERACTION AND CONVENTIONS
}

\section{INTERACCIÓN ESTRATÉGICA Y CONVENCIONES}

\author{
María Paz EsPinosa mariapaz.espinosa@ehu.es \\ Universidad del País Vasco. Bilbao Research in Decisions Games and Economics (Bridge). Spain \\ JAROMíR KovÁŔíK jaromir.kovarik@ehu.es \\ Universidad del País Vasco. Bilbao Research in Decisions Games and Economics (Bridge). Spain
}

Giovannı Pontı giuba@merlin.fae.ua.es

Universidad de Alicante. Spain

Libera Università Internazionale degli Studi Sociali (LUISS Guido Carli). Roma. Italy

\begin{abstract}
The scope of the paper is to review the literature that employs coordination games to study social norms and conventions from the viewpoint of game theory and cognitive psychology. We claim that those two alternative approaches are in fact complementary, as they provide different insights to explain how people converge to a unique system of self-fulfilling expectations in presence of multiple, equally viable, conventions. While game theory explains the emergence of conventions relying on efficiency and risk considerations, the psychological view is more concerned with frame and labeling effects. The interaction between these alternative (and, sometimes, competing) effects leads to the result that coordination failures may well occur and, even when coordination takes place, there is no guarantee that the convention eventually established will be the most efficient.
\end{abstract}

\section{KEYWORDS}

Behavioral Game Theory; Conventions; Coordination; Social norms.

\section{RESUMEN}

El objetivo de este artículo es presentar la literatura que emplea los juegos de coordinación para el estudio de normas y convenciones sociales, que se han analizado tanto desde el punto de vista de la teoría de juegos como de la psicología cognitiva. Argumentamos en este trabajo que estos dos enfoques alternativos son en realidad complementarios, dado que ambos contribuyen al entendimiento de los procesos mediante los cuales las personas llegan a coordinarse en un único sistema de expectativas autorrealizadas, en presencia de múltiples convenciones todas ellas igualmente viables. Mientras que la teoría de juegos explica la aparición de convenciones basándose en argumentos de eficiencia y comportamientos frente al riesgo, el enfoque de la psicología cognitiva utiliza en mayor medida consideraciones referidas al entorno y naturaleza de las decisiones. La interacción entre estos efectos diferentes (y en ocasiones, rivales) desemboca con frecuencia en fallos de coordinación y, aun cuando la coordinación se produce, no hay garantía de que la convención en vigor sea la más eficiente.

\section{Palabras Clave}

Convenciones; Coordinación; Normas sociales; Teoría de Juegos del Comportamiento. 


\section{INTRODUCTION}

Behavioral game theory combines the standard game-theoretic approach of strategic situations with the analysis of their psychological regularities. These regularities should be able to link the study of economic environments to the insights of (mostly cognitive) psychology (Camerer \& Loewenstein, 2003). In the words of Eric Van Damme, (1999: 204): "Without having a broad set of facts on which to theorize, there is a certain danger of spending too much time on models that are mathematically elegant, yet have little connection to actual behavior. At present our empirical knowledge is inadequate and it is an interesting question why game theorists have not turned more frequently to psychologists for information about the learning and information processing processes used by humans."

In this paper, we apply behavioral game theory to study the dynamics of conventions and social norms, that is, codes of conduct widespread enough to justify their adoption by each individual, taken individually (Lewis, 1969). Within the realm of behavioral game theory, conventions emerge as solutions of specific coordination games, i.e., strategic environments characterized by multiple (Nash) equilibria. These games are used to explain the emergence of conventions and social norms. Real-life examples that could be represented by this class of games abound: the use of a particular language, driving on the left or right, adoption of new information technologies, or the gathering of business activities in a particular place. It is only worthwhile speaking a language if others around speak the same language. Driving on the right only makes sense if others do the same; driving on the right in the UK is certainly not a smart thing to do. Whether or not to buy a fax machine depends on whether the people you communicate with have it or not. On a more large-scale level, the emergence of Silicon Valley as a centre of technological innovation comes from the concentration and coordination of activities in the 1990s of various IT firms and research facilities in the area. As we shall see, any game that has more than one equilibrium hides a potential coordination problem, which standard game theory often leaves unsolved. The interaction between theoretical and psychological insights, typical of the behavioral approach, has proven to be very useful in providing explanations on the emergence of conventional patterns.

Coordination problems display two common features. First, the potential multiplicity of (equilibrium) outcomes: given the prevailing convention, there is always an alternative set of conventions, each of which could play the same social function. It is sometimes possible to justify the selection of a given convention on the basis of its greater

*Acknowledgements: Financial support from MICINN (ECO2009-09120), MEC (SEJ 2007-62656 and Consolider-Ingenio 2010, CSD2006-00016), MIUR (PRIN 2007MCKEYA), Gobierno Vasco (DEUI, IT-313-07 and IT-223-07), Generalitat Valenciana (Research Group 03/086) and Instituto Valenciano de Investigaciones Económicas (IVIE) is gratefully acknowledged. 
efficiency, or smaller cost. This would be the standard "economic approach" to the study of social norms. However, in many situations, the explanation of the emergence of a specific convention is not as intuitive. Sometimes conventions appear to have been selected, in the words of Thomas Schelling (1963:70), by their intrinsic magnetism, and it is very difficult to recover their economic justification. Schelling defines this property using the term salience, emphasizing its inherent empirical content: "Salience could derive from pre-play communication among the players, but it could arise in other ways. It could arise by precedent. In fact, since salience is a psychological rather than a logical notion, the ways in which salience may arise are as various as the possible psychologies of the players." The second common feature is related with the difficulty of justifying the adoption of a particular convention beyond the mere fact that it is followed by everyone: its use does not seem directly associated with a rational calculation but determined, and to some extent imposed, by the social and institutional context in which economic agents operate. Under this interpretation, individuals express through conventions their nature of social subjects, rather than creatures guided solely by the pursuit of their individual preferences, as economic theory often assumes (although social preferences are being incorporated to explain human behavior, see Brandts and Fatas, 2012). Elster (1989:99) describes the tension between these two souls, the Homo economicus and the Homo sociologicus: "Of these, the former is supposed to be guided by instrumental rationality, while the behavior of the latter is dictated by social norms. The former is "pulled" by the prospect of future rewards, whereas the latter is "pushed" from behind by quasi-inertial forces."

In this paper, we shall illustrate these ideas by introducing the basics of coordination games, together with their standard treatment. We then survey some contributions which analyze conventions using behavioral game theory. As in a regular bridge table, the economic agents described by game theory suffer, more or less consciously, the consequences of their interdependence: the results obtained by each agent depend, to some extent, on the choices made by all. In the course of this review, we will refer to that branch of the theory, here defined as non-cooperative, which tries to model economic situations in which the institutional context does not allow the implementation of binding agreements.

As we noticed previously, any particular convention is always hiding a coordination game. In such games, the preferences of the players coincide, in the intuitive sense that if two people aim to meet, they should show up at the same time and place, in which case a "convention", i.e., a coordination device, can be characterized in terms of its efficiency, or lower risk in case such coordination may not take place.

As we will see, standard game theory has difficulties in predicting the outcome of coordination games. Hence, in Section 3 we show how behavioral game theory may inform game theory on the mechanics of the convention selection process. In identifying these "psychological effects", Section 4 argues that it is indeed the combination of psychological reasoning and strategic thinking what helps us to solve coordination problems in everyday life. 


\section{Coordination games}

The purpose of this section is to introduce some basic game-theoretic concepts often used to illustrate this behavioral approach to the emergence of conventions. We start with the exposition of the simplest class of strategic models, namely, $2 \times 2$ games. These are simultaneous-move games in which two players have just two options ("strategies") at their disposal. Figure 1 sketches the stereotypical coordination game, Choosing sides, where two players (call them "Ann" and "Ben") must simultaneously choose a number, either $X$ or $Y$. If their choices match, they both "win" (i.e., they get 1); if their choices do not match, they both "lose" (i.e., they get 0 ). This is the classic pattern of a coordination game: the important thing is to select the same behavior, no matter which one (and, to some extent, how, or why).

Figure 1.

Game 1: Choosing Sides

\begin{tabular}{|l|l|l|}
\hline$A \mid B$ & $X$ & $Y$ \\
\hline$X$ & 1,1 & 0,0 \\
\hline$Y$ & 0,0 & 1,1 \\
\hline
\end{tabular}

The matrix of Figure 1 reports the so called "strategic form" of the game: each row (column) corresponds to one possible strategy available to Ann (Ben), each cell of the resulting matrix contains two numbers, the first of which refers to Ann (row player), and the second to Ben (column player). Thus, the strategic form of a game specifies the following elements:

- I, the set of players (Ann and Ben, in our example);

- $S_{i}$, the strategy set for each player $i\left(\right.$ here $\left.S_{i} \equiv\{X, Y\}, i=A, B\right)$;

- $\pi_{i}(\cdot)$ defines player i's utility (or payoff) associated with all possible outcomes resulting from game play and indicates is preference ranking over the final outcomes. For example, in Game 1 Ann prefers to coordinate with Ben, although she is indifferent regarding coordinating on $(X, X)$ or $(Y, Y)$.

Game theorists often invoke Nash equilibria as game solutions, i.e., reasonable predictions on how play may evolve in specific strategic environments. Loosely speaking, a Nash equilibrium is a combination of strategies that is robust to "unilateral deviations": given the (equilibrium) behavior of the others, no player can achieve a higher payoff by deviating from equilibrium behavior. As for Game 1, there are two Nash equilibria: 
namely, $(X, X)$ and $(Y, Y)$. In both cases, each player plays the strategy that gives her the largest payoff, given the strategy of the other.

Hence, for Choosing sides, game theory provides two alternative equilibrium solutions. The coordination problem implicit in the emergence of a convention can be then rephrased as follows: which of these two Nash equilibria is going to be played? Can game theory make any prediction here? The answer is, basically, "No". Since both equilibria are identical from a strategic point of view, no game-theoretic concept can help to resolve the coordination problem implicit in the selection of a specific convention. As a result, coordination failure is likely to occur.

As mentioned above, Choosing sides can be considered as a stereotypical coordination problem. Note, though, that Game 1 is not the only possible representation of such a strategic situation. Figure 2 reports some alternative $2 \times 2$ coordination games that may serve the same purpose:

Figure 2.

Other coordination games

\begin{tabular}{|c|c|c|c|c|c|c|c|c|c|c|c|}
\hline AlB & $X$ & $Y$ & AlB & $X$ & $Y$ & AlB & $X$ & $Y$ & AlB & $X$ & $Y$ \\
\hline$X$ & 1,1 & 0,0 & $X$ & 2,2 & 0,1 & $X$ & 4,4 & 0,2 & $X$ & 1,2 & 0,0 \\
\hline$Y$ & 0,0 & 2,2 & $Y$ & 1,0 & 2,2 & $Y$ & 2,0 & 3,3 & $Y$ & 0,0 & 2,1 \\
\hline \multicolumn{3}{|c|}{$\begin{array}{c}\text { Game 2 } \\
\text { Common interest }\end{array}$} & \multicolumn{3}{c|}{$\begin{array}{c}\text { Game 3 } \\
\text { Risk Dominance }\end{array}$} & \multicolumn{3}{c|}{$\begin{array}{c}\text { Game 4 } \\
\text { Stag-Hunt }\end{array}$} & \multicolumn{3}{c|}{$\begin{array}{c}\text { Game 5 } \\
\text { Battle of the sexes }\end{array}$} \\
\hline
\end{tabular}

As Figure 2 shows, the cells on the main diagonal of all games, i.e. all cases in which both players opt for the same strategy, are Nash equilibria (and, therefore, potential conventions). However, there are also some important differences. In particular, while in Games 1 and 3 both Nash equilibria are associated with the same payoff, (1 and 2 , respectively), in Games 2 and 4 one of the two equilibria is preferred by both players, i.e., there exists a unique Pareto-efficient equilibrium. And yet, while in Games 1 to 4 players' equilibrium payoffs are always equal to each other (i.e. players value equilibria in the same way), in game 5 players differ in their evaluations on which Nash equilibrium should be selected, as Ann prefers $(Y, Y)$ since she would get 2, instead of 1 , while Ben's preferences are exactly reversed, he prefers the outcome $(X, X)$. Finally, while in games 1, 2 and 5 both strategies are associated with the same outof-equilibrium payoff pair, $(0,0)$, in Games 3 and 4 strategy $Y$ gives players a higher out-of equilibrium payoff. Hence, playing $Y$ in Games 3 and 4 is, somewhat, "less risky" (see García-Gallego et al, 201], on attitudes toward risky choices). All these examples suggest that both efficiency and risk may be used by players as criteria for evaluating the success (or failure) of a specific convention. 


\section{HOW PEOPLE BEHAVE IN COORDINATION GAMES}

This section focuses on solutions proposed by behavioral game theorists to solve coordination problems. These theories of "equilibrium selection" have received considerable attention by theorists and have been tested extensively in the lab (see the excellent surveys of Ochs, 1995 and Camerer, 2003). These selection devices are based on i) the (payoff) structure of the game (and, in this sense, rely on game-theoretic criteria); or are based on ii) psychological framing (and, in this sense, rely mostly on psychological principles).

As for the former, payoff and risk dominance, both proposed by Harsanyi and Selten (1988) in their influential book on equilibrium selection, are the main selection criteria put forward by game-theorists. A Nash equilibrium is said to be payoff-dominant if it is Paretosuperior to all other Nash equilibria in a game, that is, if another equilibrium does not exist that yields higher payoffs to all players. In this respect, the selection criterion of payoff dominance is based on collective rationality. This concept can predict the outcome of Games 2 and 4. In Games 1, 3 and 5 though, it does not solve the coordination problem, since both equilibria are equally efficient. The other criterion, namely risk-dominance, applies to all symmetric coordination games characterized by the strategic form shown in Figure 3. In this case the Nash equilibrium $(X, X)$ is said to be risk-dominant if $a+b$ $>c+d$, i.e., if the sum of payoffs associated with the use of its strategy is higher. Harsanyi and Selten (1988) justify risk-dominance on the ground of the so-called "principle of insufficient reason", first enunciated by Jakob Bernoulli, then popularized by John Maynard Keynes (1921:42), in his well-known Treatise on Probability: "if there is no known reason for predicating of our subject one rather than another of several alternatives, then relatively to such knowledge the assertions of each of these alternatives have an equal probability." In our context, the risk-dominant strategy is the one that maximizes players' expected payoffs in the absence of any view on the other player's behavior (i.e., considering either strategy equally probable). It is the strategy that minimizes the risks associated with the possibility that coordination does not take place.

Figure 3.

A symmetric $2 \times 2$ coordination game; $a>c$ and $d>b$

\begin{tabular}{|l|l|l|}
\hline AlB & $X$ & $Y$ \\
\hline$X$ & $a, a$ & $b, c$ \\
\hline$Y$ & $c, b$ & $d, d$ \\
\hline
\end{tabular}

Note that payoff dominance, as defined here, differs from the concept of strategic dominance. Payoff dominance selects among Nash equilibria (i.e. combinations of strategies for all players), while strategic dominance selects among possible strategies of a 
particular individual. For player i, strategy $X$ strategically dominates $Y$ if the payoff from playing the former always exceeds the payoff from playing the latter, independently of the behaviour of opponents. For a more formal definition, see for example Vega-Redondo (2003). The term "symmetric" refers to the fact that the strategic situation faced by each player is exactly the same: their decision problems do not depend on her role or identity. In a symmetric game, the strategy space of the players, as well as the structure of their preferences coincide. Adherence to a convention does not mean, however, that they should behave equally: at a road cross an agreement must establish who has priority, and who must give way; both drivers have the same options but the convention provides each of them with a different behavior (Sugden, 1986).

Hence, in Game 2, the equilibrium ( $Y, Y$ ) is both payoff and risk-dominant. In Game 3 , instead, both equilibria are equally Pareto efficient, but only $(Y, Y)$ is risk-dominant. Finally, Game 4, known in the literature as the 'stag-hunt game', represents a situation in which the Pareto-optimality conflicts with risk-dominance: $(X, X)$ is payoff-dominant, but $(Y, Y)$ is risk-dominant. If a player has psychological predispositions to avoid risky decisions, she may prefer to choose action $Y$ in this game.

This latter game, where exists a conflict between payoff and risk-dominance, has been extensively studied experimentally to see how subjects resolve this tension in the absence of a clear-cut theoretical predicament. In this respect, the experimental evidence shows a clear preference toward the risk-dominant solution (see, among others, Van Huyck, Battalio \& Beil $(1990,1991)$, Cooper \& John (1988) and Cooper \& Ross (1985)). These results have inspired a vast theoretical literature which highlights, often invoking evolutionary arguments, the stability properties of the risk-dominant solution, (see, among others, Crawford, 1991; Kandori, Mailath \& Rob, 1993 or Young , 1993)』

Moving towards equilibrium selection criteria based on psychological motives, Schelling (1963) introduces the concept of focal points, based on the idea -discussed earlier- that some actions are more salient than others. For example, in the case of Game 1, Shelling (1963) shows that action relabeling (from $X$ and $Y$ to Heads and Tails) leads to a very high coordination frequency on the (Heads, Heads) equilibrium. Explaining this evidence, Schelling argues that salience is a "cultural conventional priority" that enables people to coordinate on Heads. The effect of framing/relabeling has been reconfirmed in a variety of contexts in subsequent experiments (for example, Mehta, Starmer \& Sudgen, 1994; Bacharach \& Bernasconi, 1997; or Rojo, 2010).

Schelling's (1963) seminal experiments well explain his methodology in the study of coordination problems. In his well-known thought experiment, Schelling asked subjects to choose independently and without communication where in New York City they would try to meet one another. Those who chose the same meeting location as their partner would receive a positive (hypothetical) payoff, equal to that of their partner's and independent of the specific location. Those who did not would receive a zero payoff. Despite the plethora of possible meeting locations, a majority of subjects chose Grand Central Station, which was the most salient traffic hub in New York at the time, yielding a high expected coordination rate. On the basis of his results, Schelling concluded that even though traditional 
game theory allows no role for the salience of decision labels, many situations "provide some clue for coordinating behavior, some focal point for each person's expectations of what the other expects him to be expected to do" (Schelling 1963:67).

This example clearly applies to symmetric games, where players have identical preferences on which equilibrium they should coordinate on (this is the case of Games 1 to 4. On the other hand, it is almost impossible to find real-life examples in which players evaluations of the potential conventions are perfectly aligned (for example, Ann may prefer to meet at the Empire State Building, instead of Grand Central Station, simply because she leaves nearby). This is exactly the case of Game 5 , known as the Battle of the Sexes, where players have strong incentives to coordinate, but opposite views on which action to coordinate. Not surprisingly, these are the games in which coordination is more difficult to be achieved experimentally (the mismatch amounted to $52 \%$ and 59\% in Cooper, DeJong, Forsythe \& Ross, 1990 and 1994, respectively). Along similar lines, Crawford, Gneezy and Rottenstreich (2007) find evidence that labeling salience is an effective coordination device in symmetric pure coordination games (where "pure" here simply means that, like in our Game 1, all equilibria are equally efficient). However, salience performs poorly in asymmetric games, where its "magnetic power" conflicts with players' (asymmetric) incentives in following one convention, rather than another.

Which are the cognitive mechanisms that may help players to select a particular convention in this case? Rapoport (1997) designs an experiment to test whether the existence of an order of play (without any information disclosed on the actions taken along the sequence) has a psychological effect on the equilibrium selection process. The theory we presented so far abstracts from the order of the play since, if the late-mover does not observe the predecessors' actions, their information is exactly the same as first-movers (and the game can be treated as if moves were simultaneous). Nevertheless, Rapoport (1997) shows that the mere existence of an order of play reduces the mismatch rate to $34 \%$, as if both players were giving Ann a "first-mover advantage", just as if her action were observed by Benn (this would be indeed the so-called subgameperfect solution put forward by Reinhart Selten (1975) in his famous paper). Clearly, this advantage is purely fictitious (since Anna's actions are not observed), but it is sufficient, in this case, to act as a coordinating device. Since the timing influences both the first and second-movers, the chronological structure of the game makes certain outcomes more salient and coordination takes place.

\section{PSYCHOLOGY OR GAME THEORY? OR BOTH?}

Is the effect of focal points purely psychological or is it a combination of psychological focus and strategic thinking? Mehta, Starmer and Sudgen (1994) design a smart test of this issue. In their experiment, two groups of subjects are presented an identical set of options. In one group, people only choose the options they like without any further conse- 
quence on others. In the second group, payoffs depend on the number of individuals who choose the same action. If strategic thinking played no role, the frequency of individuals selecting the salient option should be roughly the same across treatments. If more people chose the focal action in the second treatment, this would provide evidence in favor of strategic thinking, since people recognize and choose the salient option more often precisely as they believe the others will do the same. In this sense, strategic reasoning reinforces the psychological ("framing") effect.

Their results clearly show that there is strategic reasoning behind the decisions of experimental subjects. For instance, choosing between "Heads" and "Tails", 76.1\% of individuals choose "heads" in the first treatment, vs. $86.7 \%$ in the second. This effect is even larger in other cases. When their English experimental subjects are asked to name a city, in the non-strategic treatment London is the most frequent option, named by $15.9 \%$ of the sample, this frequency goes up to $55.6 \%$ in the second treatment.

Herrero, Moreno and Ponti (2010) explore the role of moral principles as coordinating devices in the context of bankruptcy problems. They report an experimental study on three well-known solutions for problems of adjudicating conflicting claims: the constrained equal awards rule (which privileges, in the allocation of the estate, smaller claims), the constrained equal losses (which privileges bigger claims) and the proportional rule (in which losses are distributed proportionally to claims and, therefore, favors middle claimants). They first let groups of 3 subjects (with increasing claims) play three mechanisms designed in such a way that the unique (Nash) equilibrium allocation coincides with the recommendation of one of these three rules. In addition, they asked subjects to play an additional game, that has the property that all (and only) strategy combinations in which players coordinate on the same rule constitute a strict Nash equilibrium, leading to a 3-player version of a coordination game analogous to the Battle of the Sexes, since subjects are characterized by different claims and, therefore, strictly prefer the allocation dictated by one of the three rules over the others. While in the first three games subjects' play easily converges to the unique equilibrium rule, in the last game the proportional rule overwhelmingly prevails as a coordination device. In order to explain such a clearcut behavior, they administer a questionnaire to a different group of students, asking them to act as impartial arbitrators to solve (among others) the same problems played in the lab. Also in this case, respondents were sensitive to the framing of the questions, but the proportional rule was selected by the vast majority of respondents. This result highlights the pivotal role of the proportional rule as a coordinating device. Taking for granted (given the questionnaire results) that the proportional rule seems to better suit our subjects' sense of distributional justice in bankruptcy situations, it seems that this commonly shared moral judgment acts as a coordination device in the coordination game experiment, where both the high and the low claimants renounce to their first-best solution to ease coordination. If that were the case, the choice of the proportional rule as a coordinating device could be interpreted as evidence of the power of social norms to enhance coordination and cooperation within a society (see, among others, Gauthier, 1986; Skyrms, 1996 and Binmore, 1998). 


\section{Conclusions}

In this brief review, we have argued that the interpretation of a convention as a social norm may overshadow its strategic characterization; people usually adhere to a convention without wondering why. Nevertheless, the description of the strategic elements implied by a particular convention -modeled here in terms of a Nash equilibrium of a coordination game- may help explain how conventions are established and, in certain circumstances, why they have been selected.

On the other hand, our evidence also shows that psychological factors play an important role in determining which conventions will be selected, especially where game theory makes no prediction. Carefully designed experiments allow scholars to separate these strategic and psychological effects, showing that they are both equally important. The incorporation of psychological regularities into formal models may improve their predictive power and our understanding of social conventions.

\section{REFERENCES}

Bacharach, M. and Bernasconi, M. 1997. "The variable frame theory of focal points: An experimental study." Games and Economic Behavior 19 (1):1-45.

Binmore, K. 1998. Game Theory and the Social Contract. Volume II: Just playing. Cambridge Mass.: MIT Press.

Brandts, J. and Fatas, E. 2012. "The puzzle of social preferences." Revista Internacional de Sociología, Extra 1:113-126.

Camerer, C. F. 2003. Behavioral Game Theory: Experiments In Strategic Interaction. Princeton: Princeton University Press.

Camerer, C. F. and Lowenstein, G. 2003. "Behavioral Economics: past, present, future." Pp.3-51 in Advances in Behavioral Economics, edited by Camerer, CF, Lowenstein, G. and Rabin, M., Princeton: Princeton University Press.

Crawford, V.P. 1991. "An 'evolutionary' interpretation of Van Huyck, Battalio, and Beil's experimental results on coordination." Games and Economic Behavior 3:25-60.

Crawford, V.P., Gneezy U. and Rottenstreich Y. 2008. "The power of focal points is limited: Even minute payoff asymmetry may yield large coordination failures." American Economic Review 98 (4):14431458.

Cooper, R. and John, A. 1988. "Coordinating coordination failures in Keynesian models." Quarterly Journal of Economics 103:441-463.

Cooper, R. and Ross, T. W. 1985. "Product warranties and double moral hazard." Rand Journal of Economics, 16:103-113. 
Cooper, R., DeJong, D., Forsythe, B. and Ross, T. 1994. "Alternative institutions for resolving coordination problems: Experimental evidence on forward induction and preplay communication." Pp.129146 in Problems of Coordination in Economic Activity edited by J. Friedman. Dordrecht: Kluwer.

Cooper, R., DeJong, D., Forsythe, B. and Ross, T. 1990. "Selection criteria in coordination games: Some experimental results." American Economic Review 80:218-233.

Cooper, R., DeJong, D., Forsythe, B. and Rust, T. W. 1989. "Communication in the Battle of the Sexes Game: Some experimental results." Rand Journal of Economics 20:568-587.

Elster, J. 1989. "Social norms and economic theory." Journal of Economic Perspectives 3:99-117.

García Gallego, A., Georgantzís, N., Jaramillo-Gutiérrez, A. and Parravano, M. 2012. "The lottery-panel task for bi-dimensional parameter-free elicitacion of risk attitudes." Revista Internacional de Sociología, Extra 1:53-72.

Gauthier, D. 1986. Morals by Agreement. Clarendon Press.

Harsanyi, J. C. and Selten, R. 1988. A General Theory of Equilibrium Selection in Games. Cambridge, Mass: MIT Press.

Herrero, C., Moreno-Ternero, J.d.D. and Ponti, G. 2010. "On the adjudication of conflicting claims: An experimental study." Social Choice and Welfare 34:145-179.

Kandori, M., Mailath, G. and Rob, R. 1993. "Learning, mutation and long run equilibria in games." Econometrica 61:29-56.

Keynes, J. M. 1921. Treatise on Probability. London: Macmillan.

Lewis, D. K. 1969. Convention. A Philosophical Study. Cambridge Mass: Harvard University Press.

Mehta, J., Starmer, C. and Sudgen, R. 1994. "The nature of salience: An experimental investigation of pure coordination games." American Economic Review 84:658-673.

Ochs, J. 1995. "Coordination problems." Chapter 3 in The Handbook of Experimental Economics, edited by John H. Kagel and Alvin E. Roth, Princeton: Princeton University Press.

Rapoport, A. 1997. "Order of play in strategically equivalent games in extensive form." International Journal of Game Theory 26:113-36.

Rojo, D. 2010. "On the content of focal points." University of East Anglia, Center for Behavioral and Social Sciences, WP 10-16.

Schelling, T. 1963. The Strategy of Conflict. New York: Oxford University Press.

Selten, R. 1975. "Reexamination of the perfectness concept for equilibrium points in extensive games." International Journal of Game Theory 4(1):25-55.

Skyrms, B. 1996. Evolution of the Social Contract. Cambridge: Cambridge University Press. 
Sugden, R. 1986. The Economics of Rights, Co-operation and Welfare. Oxford: Basil Blackwell.

Van Damme, E. 1999. "Game theory: the next stage." Pp. 184-215 in Economics beyond the Millennium, edited by Gerard-Varet, L.A., Kirman, A.P. and Ruggiero, M., Oxford: Oxford University Press.

Van Huyck, J., Battalio, R. and Beil, R. 1990. "Tacit coordination games, strategic uncertainty and coordination failure." American Economic Review 80:234-248.

Van Huyck, J., Battalio, R. and Beil, R. 1990. "Strategic uncertainty, equilibrium selection principles and coordination failure in average opinion games." Quarterly Journal of Economics 106:885-910.

Young, H. P. 1993. "The evolution of conventions." Econometrica 61:57-84.

María Paz Espinosa is Professor of Economics at Universidad del País Vasco. Her research interests include game theory and experimental economics. She is currently working on group and network formation and social norms. Her publications include Quarterly Journal of Economics, Journal of Mathematical Psychology, Games and Economic Behavior, Economic Theory, Journal of Economic Methodology, Rationality and Society and Journal of Economic Behavior and Organization.

JaRomíR KovÁŔí is Assistant Professor at the University of the Basque Country. His research is interdisciplinary and focuses on social norms, social preferences and social networks, and their emergence in dynamic systems. His research articles have appeared in Economic Letters, Games and Economic Behavior and Physica $A$ among others.

Giovanni Pontı got his PhD in Economics at the University College, London, on Evolutionary Game Theory. His current research agenda is mainly focused on the activities of the Laboratory of Theoretical and Experimental Economics (LaTEx) of the Universidad de Alicante, which he founded in the year 2000 and directs ever since.

RECEIVED: 14 July 2011

ACCEPTED: 5 December 2011 